\title{
A genetic analysis of reproductive barriers in Phacelia dubia
}

\author{
FOSTER LEVY \\ Department of Botany, Duke University, Durham, North Carolina 27706, USA
}

\begin{abstract}
Investigations into the genetic basis of reproductive barriers among recognized and putative varieties in Phacelia dubia have provided evidence that even among closely related taxa, multiple pathways can lead to reproductive isolation. A nuclear-based reproductive barrier, expressed as partial hybrid sterility of both pollen and ovules, isolated each pair of recognized varieties. There was no evidence of pre- or post-fertilization barriers; all reproductive barriers were manifested as hybrid gametic sterility. Reproductive relationships of two putative varieties were studied to examine the early stages of reproductive isolation in this group. Both putative varieties exhibited partial reproductive isolation from the recognized varieties in spite of their lack of morphological differentiation from recognized varieties. The barrier isolating one putative variety was similar to the barrier among recognized varieties. The second putative variety and a recognized variety were partially isolated by a unidirectional, nuclear-cytoplasmic barrier that reduced only pollen fertility. The nuclear-cytoplasmic barrier suggested a new application of Haldane's rule.
\end{abstract}

Keywords: hybrid sterility, Phacelia, reproductive barriers, reproductive isolation, speciation.

\section{Introduction}

Speciation is a process during which genetic change becomes fixed in different lineages. The early, ecologically based approach to determining the mechanism of speciation relied upon inferences from biogeographical patterns. Probably as a result of the widespread use of this method, the most commonly held belief is that speciation involves the gradual accumulation of differences among allopatric populations (White, 1978; Lande, 1980; Barton \& Charlesworth, 1984). The introduction of common garden and transplant experiments made it possible to disentangle the genetic from the environmental components contributing to variability among taxa (Clausen et al., 1948). Powerful predictions can be offered about the mechanism of speciation only in combination with data on the genetic basis of morphological characters defining species, as well as on the reproductive barriers that isolate them. To determine the nature of the species barrier, that is, how different two taxa are genetically and in what ways they differ, requires information that can only be obtained from crosses.

A protocol to analyse the genetics of the species barrier must consist of (i) documenting the nature of

Correspondence: Department of Biological Sciences, East Tennessee State University, Johnson City, Tennessee 37614, USA. the isolating mechanism, (ii) locating the loci within the genome controlling isolation and, (iii) determining the processes that have stimulated the shifts in reproductive specificity which accompany speciation. Reproductive barriers can encompass one or more of a wide spectrum of phenomena. These vary in their time of expression from pre-mating, pre-zygotic, post-mating, to hybrid inviability and infertility barriers (Grant, 1981). Although a range of different potential barriers have been identified, most studies have assayed for only one or two of these. A full picture of the factors that contribute to reduced inter-breeding is a prerequisite to estimating the magnitude and complexity of the species barrier. Consequently, even our knowledge of step one of the protocol is incomplete. To determine the genetic basis of the traits that contribute to reproductive isolation (step two of the protocol) is the start of an analysis of the extent of the genetic change that separates two taxa. The information required consists of the number and location of loci that control expression of a particular barrier (nuclear, linked or unlinked, cytoplasmic), how these genes interact (additively, epistatically, dominance relationships), and the relative male and female parental contributions.

The major barriers uncovered in prior studies of reproductive isolation in plants include divergence in flowering time (McNeilly \& Antonovics, 1968), 
differential pollen tube growth (Buckholtz et al., 1935), reduced seed production (Vickery, 1959; Grun, 1961; Rick, 1963; Levin, 1966; Parker \& Borrill, 1968), and $F_{1}$ weakness and sterility (Michaelis, 1954; Stebbins, 1958; Chu et al., 1969; Oka, 1974). Only rarely has a detailed analysis of the genetic basis of these barriers been undertaken. Among the most thoroughly investigated examples are the nuclear loci that control $F_{1}$ sterility in rice cultivars (Oka, 1974) and the nuclear-cytoplasmic interactions leading to sterility in the genus Epilobium (Michaelis, 1954). Eventually, one would hope to identify and characterize loci that contribute to isolation among taxa.

Knowledge of the first two steps of the protocol, the nature of isolating mechanisms and their genetic bases is, at best, only partially complete. Consequently, most inferences concerning the population processes that give rise to reproductive barriers are, of necessity, mostly conjecture.

\section{Experimental approach}

To study the genetic changes that accompany speciation, it would be most instructive to investigate these differences among 'good', reproductively isolated species. Unfortunately, complete reproductive isolation precludes the use of experimental hybridizations and therefore a genetic analysis is not possible. Entities that are similar enough to produce viable offspring but that vary both in the magnitude of reproductive isolation and in the degree of morphological differentiation, would be most useful. It is necessary, therefore, to conduct these studies at a lower taxonomic level, such as comparisons among varieties within a species. The question of whether there is a tendency for a particular type of barrier to arise among closely related taxa can be addressed by the determination of which barriers exist among pairwise varieties within a species. If a particular barrier predominates, a similar mechanism may have led to reproductive isolation; if the barrier involves several genes, variation in the magnitude of that barrier among different varietal pairs may be a function of the time since divergence.

The study group, varieties within Phacelia dubia (L.) Trel. (Hydrophyllaceae), was chosen because in this species differentiation of geographical varieties appears to be an on-going process. The species consists of three taxonomically recognized, allopatric varieties, two of which are narrow endemics (Constance, 1949; Murdy, 1966; Levy, 1991). Based upon geographical, ecological, and morphological data, Levy (1991) has also proposed two additional putative varieties. Reproductive relationships among all of these varieties have been unknown prior to this study. The putative varieties, which may represent incipient varieties, were tested for reproductive barriers in the absence of apparent morphological divergence to provide insight into the early stages of differentiation. For example, it is instructive to know whether the putative varieties, when crossed with recognized varieties, express similar barriers with similar genetic bases. If this is the case, and if differences only occur in the magnitude of expression of the barrier, it may indicate a barrier in which gradual divergence eventually leads to speciation.

\section{Materials and methods}

\section{Study organism}

Phacelia dubia was chosen because subspecific varieties express a broad range of ecological, geographical, and morphological variation. In spite of this variability, the varieties within $P$. dubia constitute a monophyletic group which exhibits complete reproductive isolation from $P$. maculata Wood, their nearest relative (Constance, 1949; Gillett, 1964; Murdy, 1966). Reproductive isolation among the subspecific taxa within $P$. dubia is incomplete thereby permitting a genetic analysis. All of the varieties of $P$. dubia and $P$. maculata share a base chromosome number of $n=5$, the lowest number in the genus. Cytological analysis revealed no obvious chromosomal differences among varieties of $P$. dubia (Murdy, 1966; Levy \& Felber, unpublished data). Plants are fully self-compatible but individual flowers are protandrous (Levy, 1988).

The three formally recognized taxonomic varieties are:

1 P. dubia var. dubia (=dubia), which is the most wide ranging variety both ecologically and geographically. These plants form discrete populations in alluvial or rocky woods as well as on disturbed roadbanks, ranging from Pennsylvania to North Carolina,

$2 P$. dubia var. georgiana McVaugh (= georgiana), a taxon endemic to granitic outcrops in Georgia and Alabama and,

3 P. dubia var interior Fernald (= interior), which is also a narrow endemic. Populations of interior are restricted to cedar glades in the Nashville Basin of Tennessee.

Two proposed putative varieties were also included in this study. These are:

$1 P$. dubia var. 'imitator' (= imitator), comprised of a series of populations which, like georgiana, are restricted to granitic outcrops. Unlike georgiana, these plants possess some of the morphological characters of dubia (Levy, 1991). Populations of imitator are located 
Table 1 Habitat and location of populations of Phacelia represented in hybridjzation experiments

\begin{tabular}{llll}
\hline Taxon & Population & Habitat & Location \\
\hline Phacelia dubia var. dubia & $\mathrm{d}-1$ & Alluvial forest & High Rock, NC \\
& $\mathrm{d}-2$ & Upland forest & Claytor Lake, VA \\
P. dubia var. georgiana & $\mathrm{g}-3$ & Granite outcrop & Echols Mill, GA \\
& $\mathrm{g}-4$ & Granite outcrop & Heggie's Rock, GA \\
P. dubia var. interior & $\mathrm{j}-1$ & Cedar glade & Cedars-of-Lebanon, TN \\
P. dubia var. 'imitator' & $\mathrm{p}-1$ & Granite outcrop & York Co., SC \\
P. dubia var. 'railroad' & $\mathrm{p}-2$ & Granite outcrop & Kershaw Co., SC \\
& $\mathrm{r}-1$ & Railroad embankment & Radford, VA \\
& $\mathrm{r}-2$ & Railroad embankment & Bertin, VA \\
\hline
\end{tabular}

in South Carolina, a region between the known ranges of dubia and georgiana and,

2 P. dubia var, "railroad" ( $=$ railroad), which consists of two large populations in southwestern Virginia, within the range of and in proximity to dubia populations. Plants in these populations are restricted to a narrow linear zone of gravel-covered cinders on railroad embankments. These plants did not differ morphologically from plants in nearby dubia populations (Levy, 1991).

The habitats and locations of populations from which seeds used in this study were collected are outlined in Table 1. Population acronyms given here correspond to those in Levy (1991).

\section{The nature of reproductive barriers}

Diallel experiment. Comparisons among different populations within varieties were carried out to determine if divergence in reproductive compatibility occurred at the population level. Because there is little information on the genetic basis of any plant reproductive barrier, there were no a priori assumptions about possible barriers in $P$. dubia and several of these were assayed for. A complete diallel crossing design was employed to determine (a) whether each particular assay of reproductive compatibility was genetically based, (b) what the underlying genetic basis of each possible barrier was, that is, was it nuclear based, cytoplasmic, influenced by epistasis, etc. and (c) the differential parental influences on each potential barrier. The diallel was hierarchically arranged with four individuals from each of two populations nested within each of three varieties (Fig. 1). In the diallel three varieties (dubia, railroad and georgiana) were represented by four plants from each of two populations within each variety. The diallel was analysed both as a $6 \times 6$ populational and as a $3 \times 3$ varietal diallel. Because of the factorial nature of this design, limita- tions in time, space, and resources prohibited the inclusion of all five varieties. The baseline data from the three varieties in the diallel would serve as a reference with which more modest crossing programmes involving the remaining two varieties could be compared.

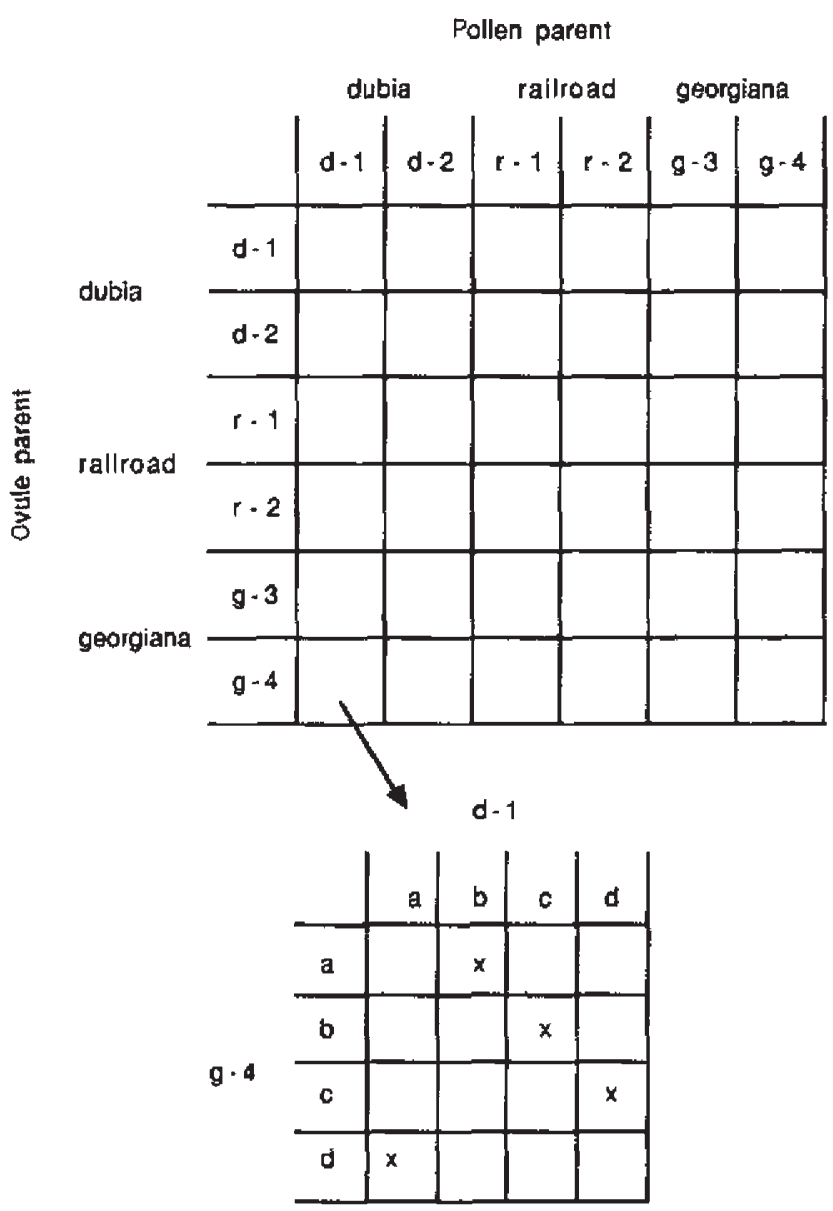

Fig. 1 Design matrix of the diallel experiment. a-d represent individual plants; $x$ 's represent plants assayed for pollen fertility. 
Table 2 Assays of reproductive compatibility and the number of replications per assay carried out in the diallel experiment. Replicates of percentage seed germination refer to the number of Petri dishes, each containing several seeds (see text); all other replicates refer to the number of plants assayed

\section{Replicates per}

Population $\times$ population cell Variety $\times$ variety cell

$\begin{array}{llr}\text { Assays on parental plants } & & \\ \text { Rate of pollen tube growth } & 16 & 256 \\ \text { Number of seeds per capsule } & 64 & \\ \text { Assays on } F_{\text {: }} \text { plants } & & 12 \\ \text { Percentage seed germination } & 3 & 16 \\ \text { Flowering time } & 4 & 16 \\ \text { Pollen fertility } & 4 & \end{array}$

An analysis of reciprocal crosses, as described in Cockerham \& Weir (1977), was performed at the population level for each assay of reproductive compatibility. In this analysis, 'nuclear' effects are indicative of additive genetic effects, 'nuclear-specific' effects indicate dominance and/or epistasis. 'Reciprocal' effects, which include maternal environment and cytoplasmic genetic components, occur when a variety consistently exhibits differential performance when crossed as the pollen versus the ovule parent. If these reciprocal effects are limited to specific cross combinations, that is, they are restricted to particular cells of the diallel rather than entire rows or columns, these are termed 'reciprocal-specific' effects (for a discussion of these effects, see Antonovics \& Schmitt, 1986). Shore \& Barrett (1985) applied a similar analysis to compare hybrids among species in the genus Turnera. Two-way ANOVAs, which treated ovule and pollen parents as main effects, were used to test for significant parental effects contributing to the various assays of crossability. The latter information could not be determined from the analysis of reciprocal crosses. Populational and varietal level results were largely indistinguishable and for simplicity only the varietal results will be presented. When significant parental effects were uncovered, means were compared by $t$-tests with the Bonferroni correction for multiple comparisons (Morrison, 1976).

The parents for the diallel crosses were grown from seeds collected in the field in the spring 1985. In January 1986 these seeds were germinated on moist filter paper at $13^{\circ} \mathrm{C}$. After the cotyledons had expanded, the seedlings were transplanted into a sand:vermiculite:gravel mixture and placed in a growth chamber in the Duke University Phytotron. Plants were watered twice daily; once with half strength Hoagland's solution and once with distilled water. They were grown at $25^{\circ} \mathrm{C}$ day $-20^{\circ} \mathrm{C}$ night under $12 \mathrm{~h}$ light for the first 45 days followed by $15 \mathrm{~h}$ light for the remainder of the experiment to simulate increasing daylength as the season progresses under natural conditions. All plants exhibited vigorous growth and flowering under these conditions. $F_{1}$ and backcross progeny were grown using similar protocols.

Flowers to be pollinated were emasculated in bud. All pollinations were carried out on the third day that a flower was open as this had previously been shown to be the time of maximal stigma receptivity in Phacelia dubia (Levy, 1988). Flowers were pollinated by touching a newly dehisced anther to the stigma of the ovule parent.

Reproductive barriers were compared to test for (a) differences among reciprocal hybrids, (b) differences between hybrids and parentals and, (c) differences among the four individual ovule parents within each category. Five assays of reproductive compatibility were measured as follows (Table 2).

1. Rate of pollen tube growth. A subset of flowers was crossed as described above and $4 \mathrm{~h}$ after pollination the entire flower was placed in formalin acetic acid, a fixative which stopped pollen tube growth. To visualize the pollen tubes, the styles were first cleared in $9 \mathrm{~N}$ $\mathrm{NaOH}$, washed in water, and stained in a 0.1 per cent solution of aniline blue dye in $0.1 \mathrm{~N} \mathrm{~K}_{3} \mathrm{PO}_{4}$ (Kho \& Baer, 1968). Pollen tubes were viewed in a Zeiss microscope equipped with an ultraviolet light source. Pollen grains, pollen tubes, callose plugs within the pollen tubes, and the ovules all fluoresced. Although pollen grains were easily visualized, there were often more pollen tubes than there were pollen grains on the stigmata which indicates a loss of grains during the specimen preparation. Thus the number of pollen tubes in the stigmatic region relative to the number of tubes at the halfway point of the style was used to 
determine the rate of pollen tube growth. Given the initiation of a pollen tube, this ratio estimates the average distance traversed by pollen tubes in a style after a fixed time period.

2. Number of seeds per capsule. At maturity, seed capsules turn from green to brown at which time the number of matured seeds per capsule was counted.

3. $F_{I}$ seed germination. Because this study was concerned with interactions among populations rather than among individual plants, each of the 36 population $\times$ population cells of the diallel was represented by seeds from four of the possible 16 plant $\times$ plant combinations within these cells (Fig. 1). Seeds that result from self-pollinations were excluded from this and further analyses to prevent confounding of inbreeding effects with reproductive barriers.

Within each of the $F_{1}$ combnations in which germination was to be studied, four to 18 seeds were placed on moist filter paper in a Petri dish treated with an initial application of Captan (Chevron Chemical Co.), a fungicide used to prevent fungal growth on germinating seeds. The seeds were germinated at $16^{\circ} \mathrm{C}$ and supplements of distilled water were added to each dish as needed. After the twenty-first day, the number of germinated seeds was counted and statistical analyses were performed on the arc-sin transformed percentage germination.

4. $F_{1}$ flowering phenology. One $F_{1}$ plant from each Petri dish described above was chosen at random to be grown to maturity. Thus, for this assay each population $\times$ population cell was represented by four plants; each variety $\times$ variety cell included 16 plants (Table 2 ). The date of first flowering was recorded for each plant with day one referring to the day the first experimental plant flowered.

5. $F_{I}$ pollen fertility. Pollen fertility was estimated on each of the $F_{1}$ plants grown to maturity by staining pollen grains in lactophenol-cotton blue solution. Pollen that imbibed the dye were darker than the background and large in size; these grains were counted as fertile. Three counts of 100 grains on each of two flowers were taken for each plant. Statistical analyses were performed on the arc-sin transformed percentage of fertile pollen.

Backcrosses of a recognized variety: dubia-georgiana hybrids. Backcrosses of $F_{1}$ hybrids to plants from each parental variety were performed to determine whether hybrids could act as a bridge for gene flow through a partial reproductive barrier. The backcrossing design consisted of four different $F_{1}$ hybrids and their reciprocals, as well as four plants each from dubia and georgiana (Fig. 2). Four dubia and two to four georgiana plants were used as pollen parents. In all backcross experiments, plants from only one population within each variety were included.

In addition to the pollen fertility assay of the diallel experiment, the following were studied: (a) the fertility of hybrid ovules relative to ovules of parental plants, (b) the difference in the rate of pollen tube growth
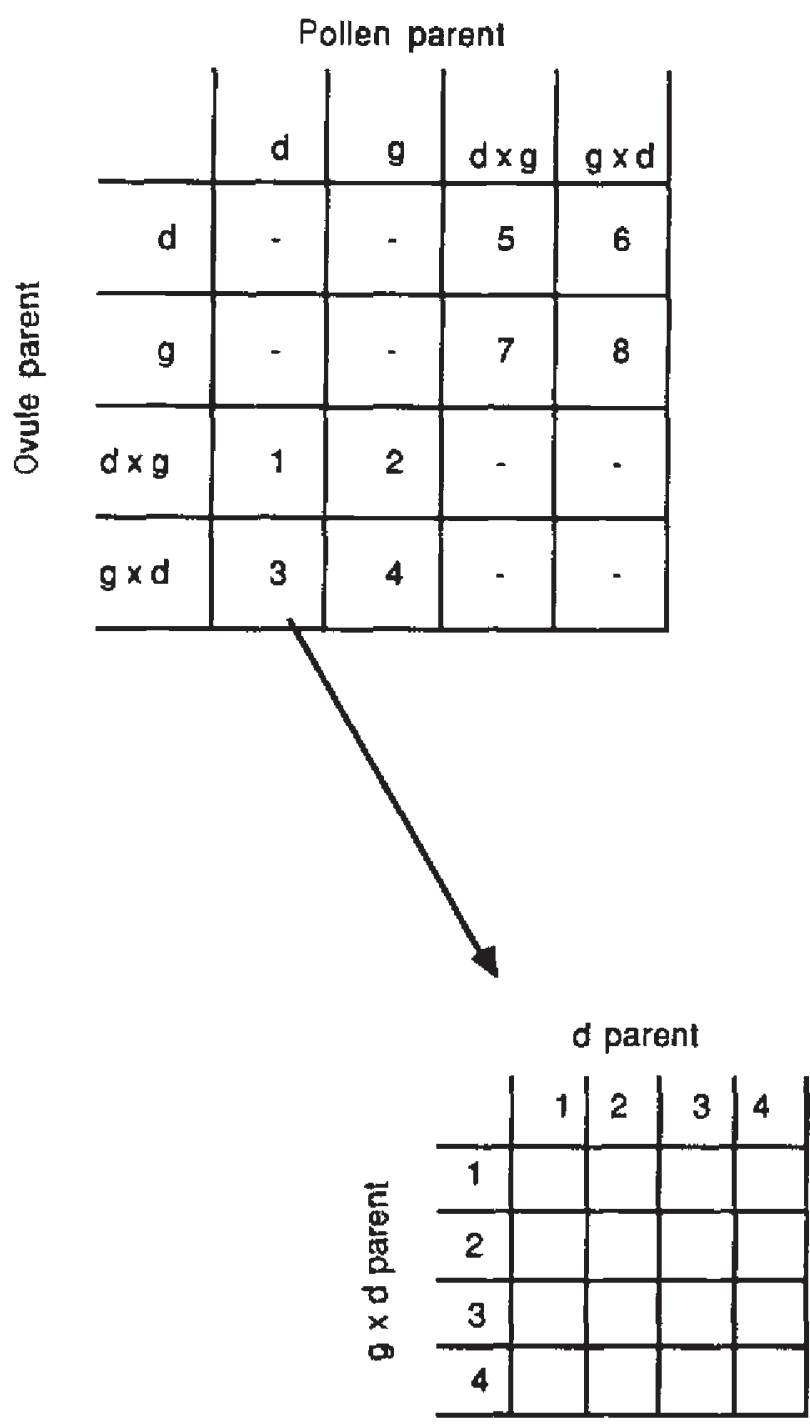

Fig. 2 Design matrix of the backcross experiment, Dashes indicate cells in which crosses were not performed. Each cell is represented by four pollen and four ovule parents as illustrated in the lower matrix. Numerical entries within celis are reference designations as referred to in the text. The number of replicates per cell varied depending upon the particular assay (see text). $\mathrm{d}=$ dubia, $\mathrm{g}=$ geogiana, $\mathrm{d} \times \mathrm{g}=$ dubia $\bigcirc \times$ georgiana $\mathrm{o}, \mathrm{g} \times \mathrm{d}=$ georgiana $\$ \times$ dubia of. A similar design was used in dubia-railroad backcrosses. 
between hybrids and parentals, (c) the ability of hybrid pollen to effect fertilization by counting the number of seeds produced from pollinations using hybrid pollen and, (d) whether backcrossed progeny exhibit a range of pollen fertilities. The last measure determines whether later generations can return to complete fertility as well as providing information about the complexity of the genetic basis of the reproductive barrier.

Hybrid ovule fertility. To determine the relative fertility of hybrid ovules, hybrid plants and their reciprocals were pollinated using pollen from each parental variety under the assumption that fully fertile pollen was most likely to effect successful pollination. Each of four ovule parents within pairs of dubia-georgiana hybrids and their reciprocals were pollinated by a different parental plant from each of the parental varieties. The number of matured seeds was counted in each of 3-24 capsules from each of these eight ovule parents. Data were analysed by ANOVA in which the pollen source was first tested to determine whether the hybrids exhibited differential receptivity dependent upon the source variety of the pollen. The success rates of reciprocal hybrids were compared to one another and to parental plants.

Hybrid pollen tube growth and effectiveness. A similar series of backcross pollinations, in this case using hybrid pollen to pollinate parental plants, were performed to test the effectiveness of hybrid pollen to sire seeds. The number of seeds per capsule produced by the dubia and georgiana ovule parents was previously determined in the diallel experiment, which had been carried out under identical growth chamber conditions. These values were used as references against which the relative success of hybrid pollen was tested.

To compare pollen tube formation and their rates of growth among hybrids and parentals, the $F_{1}$ hybrids, their reciprocals, and plants of dubia and georgiana were each crossed to an array of ovule parents consisting of plants of both parental types. Pollen tubes were assayed in three pollinations within each cell of the array. Two measures of realized pollen effectiveness were recorded: the number of pollen tubes per pollination and the ratio of pollen tubes at the base of the style to the number in the stigmatic region. In an attempt to provide an assay more sensitive to that in the diallel, these pollinations were continued for $5 \mathrm{~h}$ prior to placing the styles in the fixative. Because of the longer growth period compared to pollinations in the diallel experiment, in this experiment the ratio of the number of pollen tubes at the base of the style to the number in the stigmatic region was used to estimate the rate of pollen tube growth.

Pollen fertility of backcrossed progeny. Within each cell of the backcross design, four to seven progeny (out of

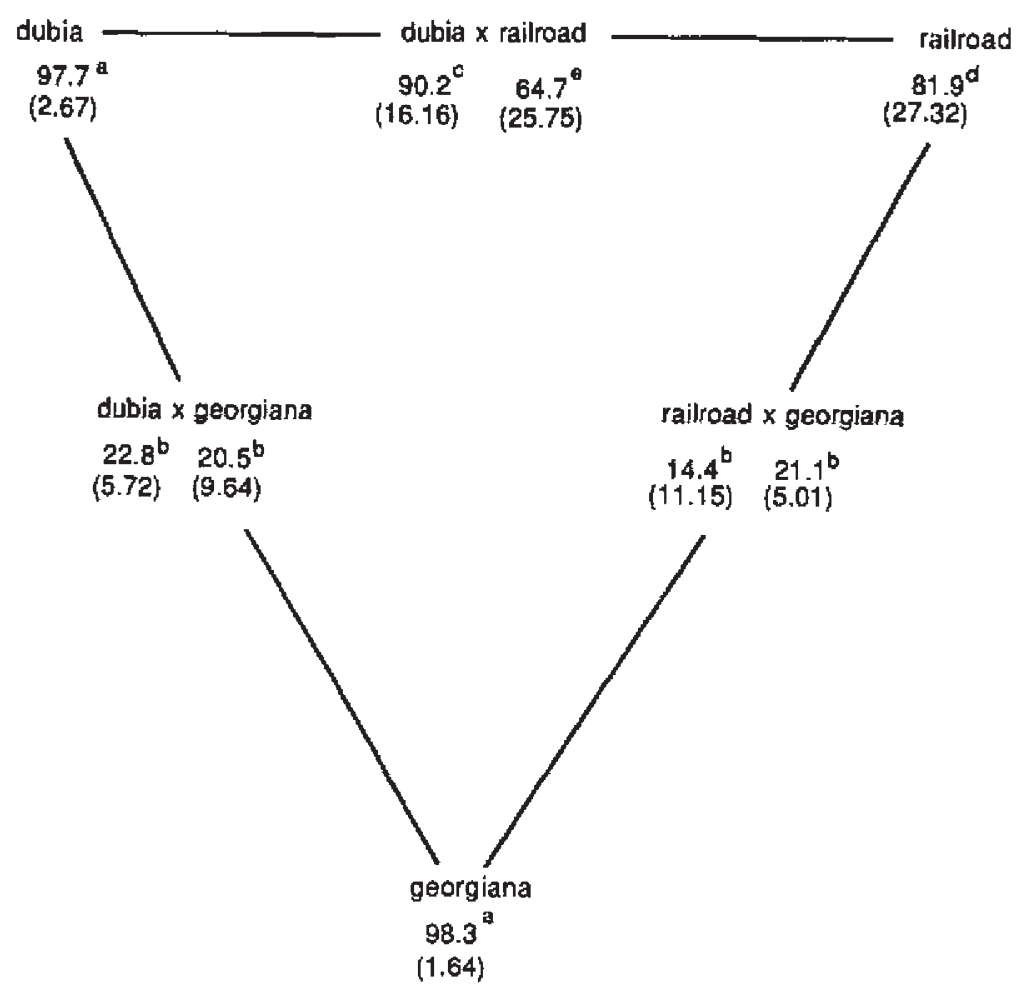

Fig. 3 Percentage of pollen fertility (standard deviations in parentheses) of $F_{1}$ plants from the diallel experiment. For inter-varietal hybrids, the value below each respective parent corresponds to the cross in which individuals of that variety acted as the ovule parent. Means followed by the same letter did not differ at $P=0.05$. $n=12-16$ plants per hybrid combination. 
16 possible) were grown to maturity and their pollen fertilities were tested by the lactophenol-cotton blue method described above. Data were analysed by ANOVA in which the two parentals of the backcross (dubia and georgiana) were the main effects with crosses to reciprocal $F_{1}$ hybrids nested within each parental. The main effect compared cells $1,3,5$ and 6 with cells $2,4,7$ and 8 while the nested effect compared cells $1+5$ with the reciprocal cells $3+6$ for the backcross to dubia; cells $2+7$ were compared to cells $4+8$ for the backcross with georgiana (Fig. 2).

Backcrosses of a putative variety: dubia-railroad hybrids. The dubia-railroad hybrids were backcrossed to parentals to test the hypothesis that the reproductive barrier between these varieties was caused by nuclear-cytoplasmic interactions. This hypothesis was suggested by significant differences in pollen fertility among dubia-railroad reciprocal hybrids. It is hypothesized that railroad populations are polymorphic for the widespread dubia cytoplasm but they also contain a novel cytoplasm in high frequency which in combination with nuclear genes from dubia results in plants with partial pollen sterility. If this hypothesis was true, one would expect genes carried by railroad pollen to produce offspring with high fertilities in the cytoplasm of dubia ovule parents. The reciprocal cross, in which dubia pollen was introduced into rail- road cytoplasm, should often result in partial pollen sterility.

The crossing design was similar to that for backcrosses of dubia-georgiana hybrids (Fig. 2). Five to eight of the 16 possible backcrossed progeny (each of different parentage) from each cell of the backcross design, were grown and tested for pollen fertility. Differences in pollen fertility of greater than \pm 10 per cent were considered significant; that is, by the methodology and number of counts per plant, there was a high probability of detecting a change in fertility of this magnitude. All changes in fertility in the dubia-railroad backcrosses are expressed relative to the fertility of the hybrid parent in the backcross, whether the hybrid was used as pollen or ovule parent. The rationale for this procedure is a result of the variation in fertility of these hybrids. Unlike dubiageorgiana hybrids, which were relatively homogeneous in terms of their pollen fertility, dubia-railroad hybrids expressed a greater range of fertility, including fully fertile plants. Therefore the fertility of a backcrossed plant must be judged relative to the fertility of the $F_{1}$ parent of that particular plant.

Hybridizations involving interior and imitator. The diallel experiment investigated the varieties dubia, georgiana and railroad. Similar, but more limited hybridization studies were carried out using interior and imitator.
Fig, 4 Mean percentage change ( $\bar{x}$ per cent) in pollen fertility of backcrossed progeny relative to the $F_{1}$ hybrid parent of each cross, $\mathrm{d}=$ dubia, $\mathrm{r}=$ railroad, $\mathrm{d} \times \mathrm{r}=$ dubia $\% \times$ railroad $\delta$, $\mathbf{r} \times \mathrm{d}=$ railroad \& $\times$ dubia 0 .
Pollen parent
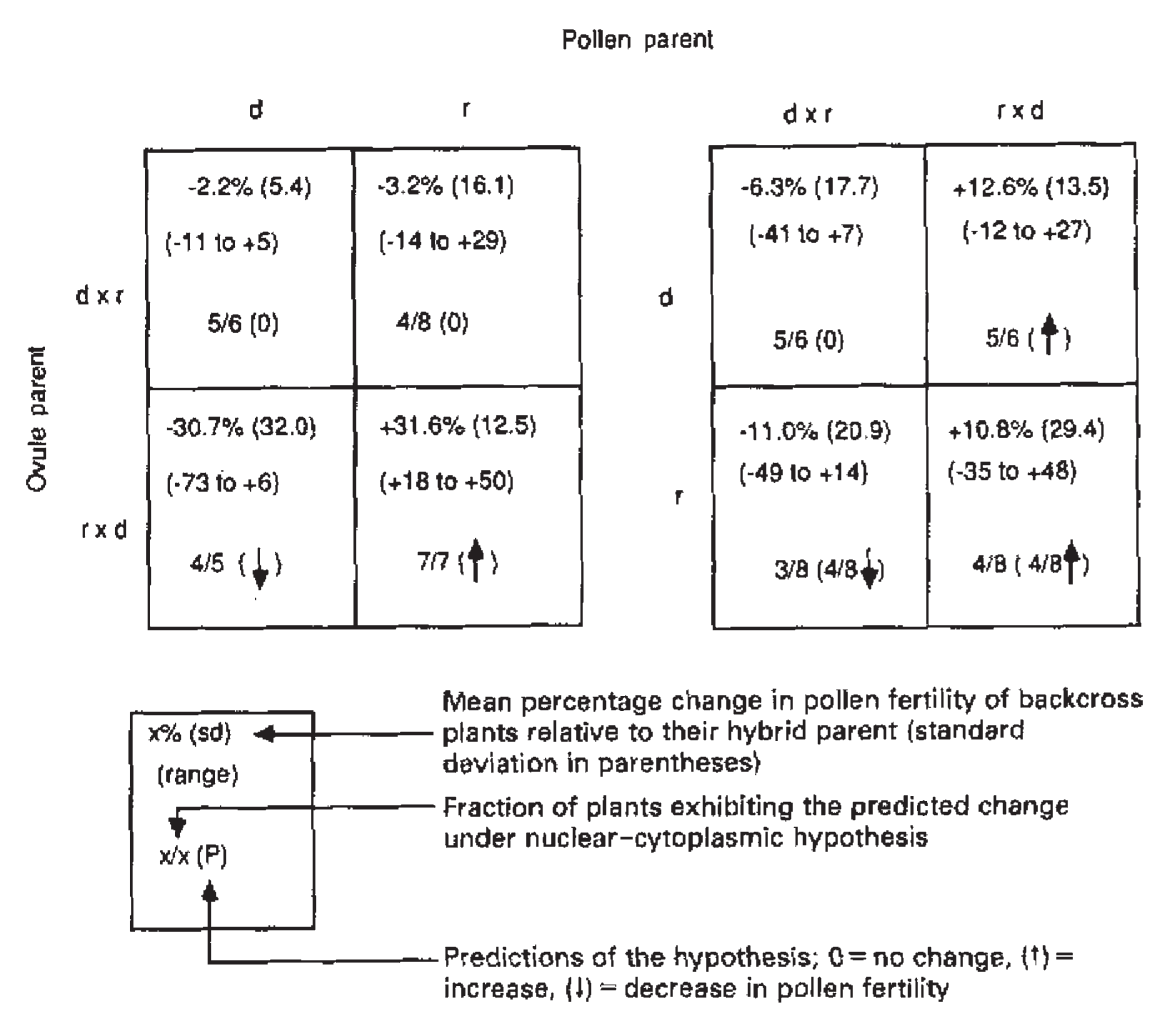


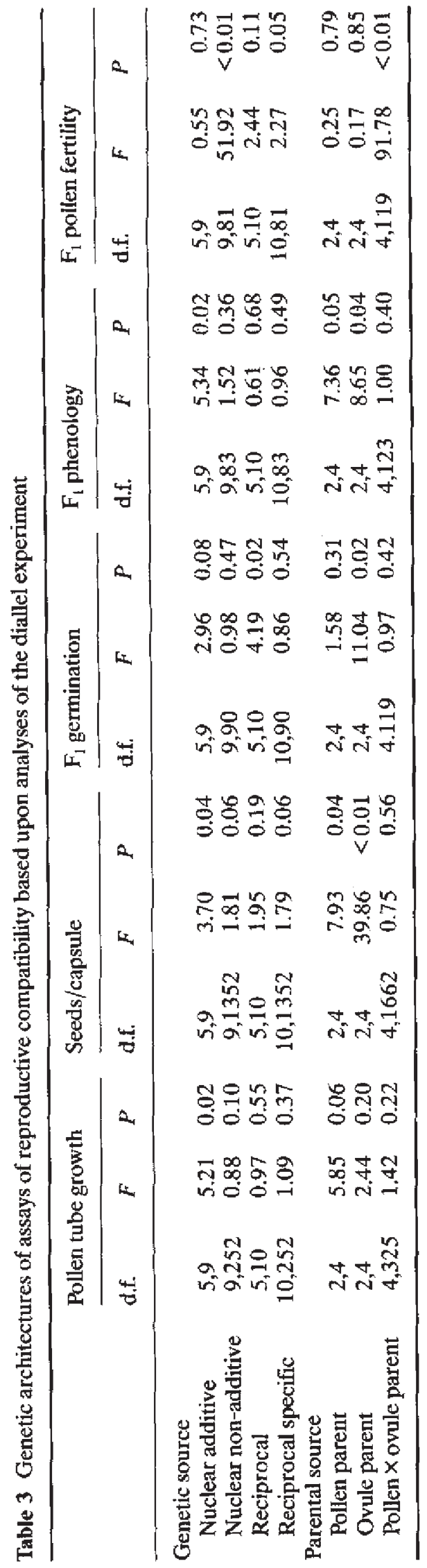

Inter-varietal hybrids involving interior. Pollen fertility of two offspring from each of four dubia (population $\mathrm{d}-1$-interior (i-1) and four georgiana (g-3)-interior (i-1) hybrids was assessed. Intra-varietal crosses within interior were omitted because prior casual crosses had determined these offspring were of high fertility.

Inter-varietal hybrids involving imitator. In a prior study, all offspring in a sample of plants grown from 100 randomly collected seeds within imitator $\left(\mathrm{p}^{-1}\right)$ were fully pollen fertile ( $>90$ per cent) when grown to maturity under growth chamber conditions similar to those used in the present study. Consequently, it was assumed that intra-populational crosses within these populations were fully fertile and the synthesis of these $\mathrm{F}_{1} \mathrm{~s}$ was not included in this study.

Hybridizations involving imitator were carried out to investigate the relationship of morphological and ecological divergence to reproductive isolation. Representatives from two populations of imitator were crossed separately to dubia and georgiana. Imitator (p-1) was morphologically similar to dubia (L,evy, 1991), but like georgiana, imitator was ecologically restricted to granitic outcrops. Four plants from imitator ( $\mathrm{p}-1)$ were hybridized reciprocally to four dubia and four georgiana plants to produce eight independent hybrids of each type. Two and three representatives from imitator $(\mathrm{p}-2)$ were crossed to two dubia and three georgiana plants respectively. Morphologically, imitator ( $\mathrm{p}-2)$ was similar to georgiana. Pollen fertility in all $F_{1}$ hybrids was measured as previously described. Data were analysed by ANOVA and crosses involving imitator $(\mathrm{p}-1)$ were tested for reciprocal effects. Means were compared by $t$ tests. Thus, the two types of barriers uncovered in the more extensive diallel design, $\mathrm{F}_{1}$ sterility and reciprocal effects, were assayed in hybridizations involving imitator.

\section{Results}

\section{The genetic basis of potential reproductive barriers}

Differentiation among varieties and populations, as indicated by analyses of the diallel, revealed that all five assays used as measures of reproductive compatibility were under genetic control. The assays differed in their genetic architectures and in the relative parental contributions to each (Table 3). Three assays, the rate of pollen tube growth, number of seeds per capsule, and $F_{1}$ phenology were controlled by nuclear-additive effects. In the former the pollen parent effect was only marginally significant and the ovule parent effect was not significant. The latter two were biparentally 
influenced which implies that $F_{1}$ hybrids are intermediate in phenotype between the parental varieties.

Pollen tubes from railroad plants grew slowly, but railroad plants produced the greatest number of seeds per capsule when used as either pollen or ovule parents (Table 4). In contrast, dubia pollen tubes grew more rapidly but these plants produced the fewer seeds when used as either the pollen or ovule parent. Phenologically, railroad plants flowered significantly later than georgiana plants but neither differed from dubia (Table 4).

There were significant reciprocal effects influencing $F_{1}$ seed germination, that is, progeny from plants used as the pollen parent differed from progeny of that same parent acting as an ovule parent (Table 3). Germination response was entirely controlled by the maternal genotypic contribution to the seed (Table 3). Seeds of georgiana ovule parents exhibited significantly lower germination, when assayed after 21 days, than did those of dubia or railroad ovule parents (Table 4).

\section{Evidence for reproductive barriers}

Although the four aforementioned assays of reproductive compatibility were all genetically based, the lack of pollen $\times$ ovule parental interactions in three of these, pollen tube growth, seed production and seed germination, indicated the absence of inter-varietal reproductive barriers (Table 3 ). Furthermore, all $F_{1}$ plants, which were subsequently grown to maturity, appeared vigorous, i.e. there were no observable differences in stature, robustness, or flower production of inter-varietal hybrids compared to progeny of intravarietal crosses.

Divergence in flowering time, the fourth assay of compatibility, may act as a pre-mating isolating mechanism in the absence of parental interactions. If hybrids flowered at a time intermediate between the parents, one would expect significant biparental additive effects. Although there was a significant additive genetic component to flowering phenology (Table 3 ), only the differences between railroad and georgiana were significant (Table 4); 8 days was the greatest difference in the date to first flowering. In light of a 2-4 week flowering season in this species, this difference probably does not represent a significant barrier to hybridization.

Pollen fertility among inter-varietal hybrids showed a highly significant parental interaction, which was in large part the result of epistatic and/or dominance relationships among the two nuclear genomes of the hybrids (Table 3 ). The source of these effects was the

Table 4 Comparisons among variety means by $t$ tests on significant parental effects in the diallel analysis. Means followed by the same letter $(a, b$ or $c)$ do not significantly differ from each other. $\bar{x}=$ mean, s.d. $=$ standard deviation, $n=$ number of replicates

\begin{tabular}{lllccc}
\hline Assay & Parent & & dubia & railroad & georgiana \\
\hline Pollen tube growth & Pollen & $\bar{x}$ & $63.8 \mathrm{a}$ & $43.3 \mathrm{~b}$ & $53.8 \mathrm{c}$ \\
(\% halfway to ovary) & & s.d. & 34.4 & 39.1 & 36.7 \\
Seeds/capsule & & $n$ & 105 & 107 & 122 \\
& Pollen & $\bar{x}$ & $2.41 \mathrm{a}$ & $3.72 \mathrm{~b}$ & $2.93 \mathrm{c}$ \\
& & s.d. & 2.66 & 3.34 & 2.50 \\
& \multirow{2}{*}{ Ovule } & $\bar{x}$ & 599 & 561 & 511 \\
& & s.d. & $2.69 \mathrm{a}$ & $3.23 \mathrm{~b}$ & $3.11 \mathrm{c}$ \\
& & $n$ & 579 & 598 & 494 \\
F $_{1}$ germination(\%) & Ovule & $\bar{x}$ & $32.7 \mathrm{a}$ & $26.6 \mathrm{a}$ & $11.0 \mathrm{~b}$ \\
& & s.d. & 29.4 & 27.9 & 13.7 \\
& & $n$ & 33 & 39 & 42 \\
F $_{1}$ phenology & Pollen & $\bar{x}$ & $18.3 \mathrm{ab}$ & $21.9 \mathrm{a}$ & $15.6 \mathrm{~b}$ \\
(days to flower) & & s.d. & 8.24 & 10.23 & 7.02 \\
& & $n$ & 46 & 46 & 40 \\
& Ovule & $\bar{x}$ & $18.5 \mathrm{ab}$ & $22.1 \mathrm{a}$ & $14.8 \mathrm{~b}$ \\
& & s.d. & 9.87 & 8.60 & 6.55 \\
& & $n$ & 43 & 46 & 43 \\
\hline
\end{tabular}


difference in fertility among intra- and inter-varietal plants (Fig. 3). F $F_{1}$ plants produced from crosses within dubia, georgiana or railroad including inter-populational crosses), were invariably of high pollen fertility (>80 per cent) (Fig. 3). Pollen fertility of the intervarietal dubia-georgiana hybrids was low $<35$ per cent) and the reciprocal hybrids did not differ from each other (Fig. 3). Raitroad-georgiana hybrids showed similar patterns of fertility. Thus, parental interactions indicative of a reproductive barrier were generated by inter-varietal hybridizations in which georgiana was one of the parents.

Inter-varietal hybrids involving interior exhibited reduced pollen fertility. Dubia-interior hybrids had significantly greater pollen fertility than georgianainterior hybrids $\left[F_{(1,6)}=14.91, P=0.008 ; \bar{x}=60.6\right.$ per cent and 46.0 per cent respectively]. There were no significant differences in pollen fertility among the individual $F_{1}$ plants within an inter-varietal combination $\left[F_{(6,8)}=2.19, P=0.15\right]$.

Partial hybrid sterility was also expressed in intervarietal hybrids involving the putative variety, imitator. Pollen fertility of inter-varietal dubia-imitator (population $\mathrm{p}-1)$ hybrids was significantly greater than georgiana-imitator $(\mathrm{p}-1)$ hybrids $\left[F_{(1,2)}=37.00\right.$, $P=0.03 ; \bar{x}=64.2$ and 44.3 per cent respectively]. Reciprocals within hybrid combinations did not differ from each other $\left[F_{(2,12)}=0.22, P=0.81\right]$. The fertility relationships among hybrids involving imitator $(\mathrm{p}-2)$ were similar; dubia-imitator ( $\mathrm{p}-2$ ) hybrids had significantly higher pollen fertility than georgiana-imitator $(\mathrm{p}-2)$ hybrids $\left[F_{(1,3)}=32.86, P=0.01 ; \bar{x}=61.8\right.$ and 50.0 per cent, respectively].

Pollen fertility was subject to significant reciprocalspecific effects (Table 3) which arose as a result of dubia-railroad hybridizations. In this hybrid combination, reciprocal hybrids differed significantly (Fig. 3); when dubia was the ovule parent, $\mathrm{F}_{1}$ hybrids were generally of high fertility but in the reciprocal cross pollen fertility was lower and exhibited a wider range of variation. Confirmation of these reciprocal effects in $d u$ bia-railroad hybrids was provided by four true reciprocal crosses among individual pairs of plants. In each case, when the railroad plant was the ovule parent, the hybrid was lower in pollen fertility than the reciprocal hybrid; the mean difference among these reciprocal hybrids was 30.5 per cent. In contrast, the seven pairs of true dubia-georgiana and railroadgeorgiana reciprocal hybrids differed by an average of only 7.6 per cent; none exceeded 18 per cent and six of the seven differed by less than 12 per cent. Moreover, crosses among plants within raitroad occasionally resulted in plants with reduced pollen fertility as evidenced by the relatively high standard deviation and somewhat lower mean fertility among railroad intravarietal crosses (Fig. 3).

\section{Hybrids as potential sources of gene flow: dubia-georgiana backrosses}

In backcrosses, there was no difference in effectiveness between the two parental sources of pollen, that is, dubia and georgiana pollen were equally functional in effecting fertilization of either hybrid combination $\left[F_{(1,6)}=0.87, P=0.39\right]$. Hybrids as ovule parents produced approximately half the number of seeds as the parentals $\left\{\bar{x}=1.47\right.$ and 2.99 respectively; $F_{i 3,10 j}$ $=14.51, P=0.001]$ with no significant differences among reciprocal $F_{1}$ hybrids or among the parentais.

Seed production following pollination of parental plants with hybrid pollen resulted in as many seeds as pollinations using parental pollen $\left[F_{(1.3)}=1.12\right.$, $P=0.38$ ] with no significant differences in performance between polien parents from the reciprocal hybrids $\left[F_{(1,6)}=0.86, P=0.52\right]$. Although the majority of pollen grains were sterile, these hybrids produced enough functional pollen to result in full seed set.

Hybrid pollen produced significantly fewer pollen tubes per pollination compared to pollen from parental sources $\left[F_{\{1,2]}=31.16, P=0.03 ; \bar{x}=2.21\right.$ and 6.76 respectively]. Furthermore, only 48.1 per cent of the hybrid pollen tubes reached the ovary within $5 \mathrm{~h}$ compared to 70.2 per cent of the parental pollen tubes; this represented a significant difference in growth rate $\left[F_{1,2\}}=127.50, P=0.008\right]$. Although there were only four to seven individuals assayed for pollen fertility within each cell of the backcross design, there was a range of expression in this trait such that within each cell of the design there were fully fertile (>90 per cent) backcrossed progeny as well as plants retaining hybrid levels of pollen fertility ( $<35$ per cent). Pollen fertilities of backcrossed progeny derived from reciprocal $F_{t}$ hybrids (within each of the two parentals to which plants were backcrossed) did not differ significantly $\left[F_{(2,4)}=2.08, P=0.48\right]$ and neither did the backcross progeny differ from either parental $\left[F_{(1,2)}=0.03\right.$, $P=0.88$. Backcrosses to dubia and georgiana had mean (standard deviation) fertilities of 53.1 per cent (35.96) and 53.0 per cent (35.85) respectively $(N=22$ to each parental). The high standard deviations were indicative of segregation within each backcross.

\section{Nuclear-cytoplasmic interactions: dubia-railroad backcrosses}

Backcrosses of dubia-railroad hybrids to each of the parental varieties showed that when hybrid plants 
acted as ovule parents in the backcross, there were no significant differences in seed production either among reciprocal $F_{1}$ hybrids $\left[F_{(1.6)}=0.84, P=0.40\right]$, among parentals $\left[F_{(1,6)}=1.02, P=0.35\right]$, or between hybrids and parentals $\left[F_{(3,12)}=0.76, P=0.54\right]$. The pollen of reciprocal hybrids was similar in ability to sire mature seeds $\left[F_{(1,1)}=1.15, P=0.48\right]$ and in this regard, hybrids did not differ significantly from parentals $\left[F_{[3,12]}=0.58\right.$, $P=0.60]$. There were significant differences among ovule parents within the two hybrid and the two parental types $\left[F_{\langle 6,6)}=7.90, P=0.01\right.$ and $F_{(6,6)}=5.13$, $P=0.03$ respectively]. Individual parental pollen parents also differed in their success when pollinating within hybrid combinations $\left[F_{(1,6)}=7.30, P=0.04\right]$.

The backcross design facilitated tests of the following predictions. If the hypothesis that dubia nuclear genes were non-functional in railroad cytoplasm was correct, the (railroad o $\times$ dubia o) $\% \times$ dubia of backcross (cell 3 in Figs 2 and 4 ), which resulted in a greater proportion of the dubia nuclear complement in the railroad cytoplasm, should have produced a decrease in fertility. Backcrossing the largely fertile (dubia $q \times$ railroad $\left.0^{\circ}\right)$ o to railroad $\%$ presented an opportunity to form de novo partial sterility (at least 50 per cent of the time, i.e. when the dubia nuclear genes of the pollen parent, present at a frequency of 0.5 in the hybrid, were passed on to the railroad cytoplasm of the ovule parent). In contrast, crossing the partially sterile (railroad $\% \times$ dubia 0 ) o to dubia $\%$ (cell 6 in Figs 2 and 4) transferred the nuclear complement of genes from the restrictive railroad cytoplasm to permissive dubia cytoplasm. Under the proposed hypothesis, these offspring were expected to be higher in fertility compared to the hybrid parent.

In the three backcrosses in which all offspring were expected to exhibit a change in pollen fertility (Fig. 4), $7 / 7$ and $5 / 6$ of the progeny showed increases (cells 4 and 6 in Fig. 4; mean increase $=31.6$ and 12.6 per cent respectively) where this was the predicted outcome and where the expectation was a decrease in pollen fertility (cell 3), 4/5 of the progeny did exhibit a decrease (mean decrease $=30.7$ per cent) (Fig. 4 ).

In two of the three cells (cells 1 and 5 in Fig. 4) of the backcross design, where no change in pollen fertility was expected, only $1 / 6$ of the offspring within each cell differed by more than 10 per cent from the hybrid parent of that offspring (mean change $=-2.2$ and -6.3 per cent, respectively). Only in cell 2 , where no appreciable change was expected, was there an unpredictable result in that $4 / 8$ of these progeny varied in fertility relative to the hybrid parent, but the mean change in this cell was only -3.2 per cent (Fig. 4).

In cells 7 and 8 , only 50 per cent of the progeny were expected to differ in fertility from their hybrid parents. The fully fertile dubia $\$ \times$ railroad $\delta$, when used as a pollen parent, provided an opportunity ( 50 per cent of the time) to introduce incompatible dubia nuclear genes into the railroad cytoplasm; in cell 7,3/8 of the progeny were lower in fertility than their hybrid parent. In cell 8 , where there was already a high proportion of partially sterile hybrids, the hypothesized restrictive railroad cytoplasm was retained in the backcrossed progeny but there was an opportunity to replace incompatible dubia nuclear genes with compatible railroad genes. In fact, $4 / 8$ of the progeny from these crosses did exhibit increased fertility.

\section{Discussion}

Investigations on the nature of reproductive barriers. Relationships among recognized varieties

Partial reproductive isolation was expressed in hybrids among all pairwise combinations of the three recognized varieties. Each combination produced viable seeds which germinated and grew into hybrid plants that were indistinguishable from parental plants in vegetative vigour. All hybrids produced a proportion of sterile pollen, and in the one hybrid combination examined (dubia-georgiana hybrids), a proportion of sterile ovules. Thus, in inter-varietal hybrids both gametes were affected, which indicates a generalized meiotic problem.

Backcrossing dubia-georgiana hybrids to each parental variety resulted in a range of fertility values within each progeny group; some of these progeny were fully fertile. The production of fertile backcross progeny occurred regardless of the direction of the cross, that is, hybrids that act as either pollen or ovule parents resulted in some fully fertile offspring. If secondary contact should occur, these results indicate a strong potential for the flow of both nuclear and cytoplasmic genes through the reproductive barrier. Although there were no quantitative estimates of pollinator effectiveness, populations of both dubia and georgiana wete observed to be visited by similar pollinators, small Halictid and Andrenid bees and honeybees. This observation, in combination with ecological differences among varieties, the localization of their respective habitats to different geographical regions, and an apparent absence of pre-zygotic barriers argues for an allopatric mode of differentiation in $P$. dubia.

It is not possible from the current data to distinguish between genic and chromosomal causes of sterility. In each of the backcross progenies, there was a range of pollen fertility levels which suggests that the sterility is controlled by more than a single locus. Possibly these varieties differ in genes that regulate meiotic pairing. 
Alternatively, the restricted expression of the reproductive barrier to meiosis in hybrids could be caused by structural differences among the parental chromosomes: for example, the parental chromosomes may differ by inversions or reciprocal translocations. If this was the case, the variation in fertility of backcrossed progenies could result from multiple translocations and/or altered segregation ratios of alternate and adjacent chromosomes (Burnham, 1962; Rickards, 1983).

\section{Does reproductive isolation precede morphological divergence?}

Two putative varieties were included in this study to examine the early stages in the formation of reproductive barriers and to determine whether reproductive isolation could precede morphological divergence. Neither of these, imitator and railroad, were unique in regard to the floral and vegetative characters which form the basis of varietal recognition (Levy, 1991). However, both were partially reproductively isolated from all other varieties they were hybridized to, which demonstrates that reproductive isolation may develop prior to morphological differentiation. The morphology of railroad plants was similar to that of plants in nearby dubia populations with which they exhibited a nuclear-cytoplasmically based partial reproductive barrier. However, when railroad was hybridized with georgiana, there were no differences in fertility among the reciprocal hybrids (Fig. 3) and the fertility levels of these hybrids did not differ from dubia-georgiana hybrids. If we consider georgiana as a tester strain in crosses with dubia and railroad, the similarity of the two hybrid combinations and their reciprocals suggested a similar set of genes in dubia and railroad contributed to their respective barriers with georgiana. Furthermore, different loci must have been responsible for the dubia-railroad barrier.

Unlike railroad, which is restricted to a small region within the range of dubia, imitator is more widespread. It is found throughout central and northern South Carolina in a region neighbouring, but not overlapping, with georgiana to the south and dubia to the north. These populations were not derived from recent dubia-georgiana hybridizations as evidenced by (a) complete fertility of plants within populations, (b) a corolla morphology in imitator (population p-1) typical of that in dubia despite the simple dominance of the georgiana phenotype in this trait (Levy, 1991) and, (c) electrophoretically, alleles common in dubia were absent from imitator populations (F. Levy, unpublished data). Nevertheless, it is impossible to rule out the derivation of imitator from more ancient hybridizations and introgression.

\section{Two pathways to reproductive isolation}

In all crosses, including those involving putative varieties, reproductive barriers were manifested as partial hybrid sterility. There was no evidence of preor post-zygotic barriers; all hybridizations resulted in viable seeds. The various hybrids differed only in their magnitude of expression of the barrier, that is in the degree of sterility. All except one pair of varieties were isolated by a nuclear-based barrier. The barrier that isolates a recognized putative varietal pair (dubia-railroad) was exceptional in three aspects: it was the result of nuclear-cytoplasmic interactions, sterility was unidirectional, and although viable hybrids were produced, only pollen exhibited partial sterility. Thus, in this group there was a tendency for a particular type of barrier to arise among what appear to be independently derived, allopatric taxa; however, the barrier may have arisen through different genetic pathways.

\section{Asymmetrical reproductive barriers}

Differences in pollen fertility among dubia-railroad reciprocal hybrids (Fig. 3), both at the varietal and individual level (as evidenced by the 'true' reciprocal hybrids), suggest that sterility may have been cytoplasmically based or the result of nuclear-cytoplasmic interactions. Backcrossing these hybrids to each of the parental varieties supports the nuclear-cytoplasmic hypothesis. In backcrossed progeny which carried the railroad cytoplasm, increases or decreases in fertility relative to their $F_{1}$ hybrid parent were dependent upon the proportion of railroad nuclear genes carried by the pollen parent (Fig. 4). In contrast, in the dubia cytoplasm, both dubia and railroad nuclear genes were usually functional. The dubia-railroad barrier was therefore unidirectional.

The observation of male sterile individuals within each of the railroad populations provides additional support for the nuclear-cytoplasmic hypothesis. Genetic studies have shown that male sterility in these populations was cytoplasmically based with at least two nuclear restorer loci interacting with the cytoplasm to influence fertility (F. Levy \& L. Broaddus, unpublished data). In these populations, a novel cytoplasm may have arisen, increased in frequency as a result of greater seed production by male sterile plants (Table 4), with subsequent selection for plants carrying complementary nuclear alleles to restore fertility. The restorer alleles are functional in both the dubia and railroad cytoplasms but alleles at these same loci in dubia populations are non-complementary in the railroad cytoplasm which results in a unidirectional reproductive barrier. One can speculate that diver- 
gence in railroad populations has been recent because these populations occupy a newly created man-made habitat.

Asymmetries in reproductive barriers have been documented in numerous studies of plants and animals. The phenotypic manifestations of differences among reciprocal hybrids in plants include differential rates of pollen tube growth (a pre-zygotic effect) (Buckholtz et al., 1935), differential seed production (a post-zyotic effect) (Grun, 1961; Levin, 1966; Duvall \& Biesboer, 1988) and differences in hybrid viability and fertility (Michaelis, 1954; Stebbins, 1958; Rick, 1963; Chu et al., 1969; Strid, 1970; Oka, 1974). In animals, the most well documented examples are found in Drosophita where sperm motility and egg viability have been used as assays of fertility. In interspecific hybrids of Drosophila persimilis and D. pseudoobscura, Orr (1987) found a large X chromosome effect on male and female fertility. At the subspecies level Orr (1989) observed a strong maternal effect on male sterility in crosses between the USA and Bogota strains of $D$. pseudoobscura. Based upon analyses of sterility patterns among closely related taxa, Coyne \& Orr (1989) argued that both male and female sterility originate early in speciation as an asymmetrical barrier. In crosses among a closely related species pair, Drosophila mojavensis and $D$, arizonensis, Vigneault \& Zouros (1986) also found an asymmetry in hybrid fertility but it was due to interactions among the $X$ and $\mathrm{Y}$ chromosomes; in these hybrids there were no maternal or cytoplasmic effects.

\section{Unisexual barriers and a new application of Haldane's rule}

The second unique characteristic of dubia-railroad hybrids, restriction of the sterility to only one sex, is an effect commonly encountered in Drosophila hybrids (Orr, 1987, 1989; Coyne \& Orr, 1989; Orr \& Coyne, 1989). Coyne (1984, 1985a,b) and Orr \& Coyne (1989) have repeatedly demonstrated the applicability of Haldane's rule to patterns of isolation among sibling species [Haldane's rule states that in a hybrid, if only one sex is sterile, it is more often the heterogametic sex (Haldane, 1922)]. Their studies have shown that male sterility (males are the heterogametic sex in Drosophila) is largely due to the interaction of genes on the $\mathrm{X}$ chromosome with other chromosomes and/or the cytoplasm.

In Phacelia, as in most flowering plants, there are no sex chromosomes. However, as often observed in Drosophila hybrids, in dubia-railroad hybrids only the male gametophytes, pollen, were sterile. This apparent contradiction may not be so surprising when one con- siders that there exists a genetically based physiological basis for pollen, and not ovule, sterility. Studies of numerous plant species have shown that pollen sterility often results from nuclear-cytoplasmic interactions (Kheyr-Pour, 1980; Van Damme, 1983; Kesseli \& Jain, 1984; Boutin et al., 1987). In several species a strong correlation of mitochondrial genotype with male sterility has implicated the plant mitochondrial genome as a controlling factor in pollen development (Warmke \& Lee, 1977; Pring \& Levings, 1978; Forde \& Leaver, 1980; Powling, 1981; Dixon \& Leaver, 1982; Leaver \& Gray, 1982).

Pollen sterility in hybrids is often caused by the merging of incompatible combinations of nuclear and cytoplasmically encoded alleles. Within populations of each parental species, complementary interactions among resident alleles result in the production of normal gametes. The intervarietal hybridization patterns in Phacelia and other flowering plants suggest a new application of Haldane's rule, one based upon genomic interactions: when gametes are dependent upon information encoded on two genomes, the sex most sensitive to heterogenomic interactions will be the one more likely to exhibit interspecific hybrid sterility.

\section{The development of reproductive barriers}

In a literature review, Coyne \& Orr (1989) demonstrated a strong correlation between the degree of taxonomic divergence in Drosophila and the nature of the species barrier. There was a tendency for prezygotic isolation to arise early in the divergence process and for it to evolve rapidly. Recently separated taxa were characterized by a post-zygotic barrier in which only males are sterile, a consequence of the propensity for beneficial recessive alleles with pleiotropic effects on reproduction to accumulate on the $\mathrm{X}$ chromosome. A gap in time occurred prior to the later development of female sterility leading Coyne \& Orr (1989) to conclude that male sterility is a natural early step in the speciation process.

Because of the paucity of studies in plants assaying for both male and female sterility, similar generalizations are premature. However, in Phacelia dubia, which consists of very closely related taxa, hybrids between two recognized varieties, dubia and georgiana were separated by a nuclear-based barrier manifested as reduced fertility of male and female gametes in hybrids. The barrier in the hypothesized incipient variety, imitator, was similar to that isolating the recognized varieties but, the dubia-railroad barrier was nuclear-cytoplasmically based, unidirectional, and only male gametes were sterile. At least in Phacelia, 
multiple pathways can lead to reproduce isolation and these do not necessarily pass through a stage of unisexual sterility. To determine whether the development of reproductive isolation in plants parallels that in animals will requite data from more species, including some in which sex determination is chromosomal.

\section{Acknowledgements}

The insightful comments contributed by M. Uyenoyama are greatly appreciated. Both J. Antonovics and $M$. Uyenoyama were instrumental in the design and formulation of these experiments. J. Antonovics, N. Gillham, T. Meagher, D. Stone, and E. Walker provided helpful comments on earlier drafts of the mantscript. D. Burdick helped with the statistical analyses and M. Rausher kindly provided a computer program for the analysis of reciprocal crosses. $D$. Stone provided assistance and laboratory space for the pollen tube analyses. This research was supported in part by funds from NIH grant \# 5 T32 GM07754-09 and NSF grant \# BSR-8613803.

\section{References}

ANTONOnics, J. AND SCHMTt, J. 1986. Paternal and maternal effects on propagule size in Anthoxanthum odoratum. Oecologia (Berlin), 69, 277-282.

GARTON, N. H. AND CHARLESWORTH, B. 1984. Genetic revolutions, founder effects, and speciation. Ann. Rev. Ecol. Syst., 15, 133-164.

BOUTIN, V., PANNENBECKER, G., ECKE, W., SCHEWE, G., SAUMITOULAPRADE, P., JEAN, R., VERNET, P. ANO MICHAELIS, G. 1987. Cytoplasmic male sterility and nuclear restorer genes in a natural population of Betu maritima: Genetical and molecular aspects. Theor. Appl. Genet., 73, 625-629.

BUCKHOLTZ, J. T., WILLIAMS, L. F. AND BLAKESLEE, A. F. 1935. Pollen tube growth of ten species of Datura in interspecific pollinations. Proc. Natl. Acad. Sci. USA, 21, 651-656.

BURnham, C. R. 1962, Discussions in Cyrogenetics. Burnham, Minneapolis, $\mathrm{MN}$.

CHU, Y.E, MORISHIMA, H. AND OKA, H.I. 1969. Reproductive barriers distributed in cultivated rice species and their witd relatives. Jap. J. Genet., 44, 207-223.

ClAuSEN, J, KECK, D. D. AND HIESEY, W. M. 1948. Experimental studies on the nature of species. III. Environmental responses of climatic races of Achillea. Carnegie Inst. Wask. Publ. 581., Washington DC.

COCKERHAM, C. C. AND WEIR, B. s. 1977. Quadratic analysis of reciprocal crosses. Biometrics, 33, 187-207.

CONSTANCE, L. 1949. A revision of Phacelia subgenus Cosmanthus (Hydrophyllaceae). Contr. Gray Herb., 168, $1-48$.

COYNE, J. A. 1984. Genetic basis of male sterility in hybrids between two closely related species of Drosophila. Proc. Natl. Acad. Sci., USA, 81, 4444-4447.

COYNE, J. A. 1985a. Genetic studies of three sibling species of Drosophila with relationship to theories of speciation. Genet. Res., 46, 169-192.

COYNE, J. A. 1985b. The genetic basis of Haldane's rule. Nature, 314, 736-738.

COYNE, J. A. AND ORR, H. A. 1989. Patterns of speciation in Drosophila. Evolution, 43, 362-381.

DIXON, L. K. AND LEAVER, C. J. 1982. Mitochondrial gene expression and cytoplasmic male sterility in Sorghum. Plant Mol. Biol, 1, 89-102.

DUVALL, M. R. AND BIESBOER, D. D. 1988. Non-reciprocal hybridization failure in crosses between annual and wildrice species (Zizania painstris $\times Z$. aquatica; Poaceae). Syst. Bot., 13, 229-234.

FORDE, B. G. AND LEAVER, C. J. 1980 . Nuclear and cytoplasmic genes controlling synthesis of variant mitochondrial polypeptides in male-sterile maize. Proc. Natl. Acad. Sci., USA, 77, 418-422.

GiLLETT, G. W. 1964. Genetic barriers in the Cosmanthus Phacelias (Hydrophyllaceae). Rhodora, 66, 359-368.

GRANT, v. 1981. Plant Speciation. 2nd edn, Columbia University Press, New York.

GRUN, P. 1961. Early stages in the formation of internal barriers to gene exchange between diploid species of Solanum. Am. J. Bot., 48, 79-89.

HALDANE, J. B. S. 1922 . Sex ratio and unisexual sterility in animal hybrids. $J$. Genet., 12, 101-109.

KESSELI, R. AND JAIN, S. K. 1984. An ecological genetic study of gynodioecy in Limnanthes douglasii (Limnanthaceae). Am. J. Bot., 71, 775-786.

KHEYR-POUR, A. 1980, Nucleo-cytoplasmic polymorphism for male sterility in Organeum vulgare L. J. Hered., 71, 253-260.

KHO, Y. O. AND BAER, J. 1968. Observing pollen tubes by means of fluorescence. Euphytica, 17, 298-302.

LANDE, R. 1980. Genetic variation and phenotypic evolution during allopatric speciation. Am. Nat., 116, 463-479.

LEAVER, C. J. AND GRAY, M. W. 1982. Mitochondrial genome organization and expression in higher plants. Ann. Rev. Pl. Physiol., 33, 373-402.

LEvin, D. A. 1966. The Phlox pilosa complex: Crossing and chromosome relationships. Brittonia, 18, 142-162.

LEVY, F. 1988. Effect of pollen source and time of pollination on seed production and seed weight in Phacelia dubia and P. maculata (Hydrophyllaceae). Am. Midl. Natur, 119, 193-198.

LEVY, F. 1991. Morphological differentiation in Phacelia dubia and P. maculata Rhodora, 93, 11-25.

MCNEILLY, T. AND ANTONOVICS, J. 1968. Evolution in closely adjacent plant populations. IV. Barriers to gene flow. Heredity, 23, 205-218.

Michaelis, P. 1954. Cytoplasmic inheritance in Epilobium and its theoretical significance. Adv. Gen., 6, 287-401.

MORRISON, D. F. 1976. Multivariate Statistical Methods. McGraw-Hill, New York. 
MURDY, w. H. 1966. The systematics of Phacelia maculata and Phacelia dubia var. georgiana, both endemic to granite outcrop communities. Am. J. Bot., 53, 1028-1036.

OKA, H.-l. 1974. Analysis of genes controlling $F_{1}$ sterility in rice by the use of isogenic lines. Genetics, 77, 521-534.

ORR, H. A. 1987. Genetics of male and female sterility in hybrids of Drosophila pseudoobscura and $D$. persimilis. Genetics, 116, 555-563.

ORR, H. A. 1989. Genetics of sterility in hybrids between two subspecies of Drosophila. Evolution, 43, 180-189.

ORR, H, A. AND COYNE, J. A. 1989. The genetics of post-zygotic isolation in the Drosophila virilis group. Genetics, 121, 527-537.

PARKER, P. F. AND Borrill, M. 1968. Studies in Dactylis. I. Fertility relationships in some diploid subspecies. New Phytol., 67, 649-662.

POWLNG, A 1981. Species of small DNA molecules found in the mitochondria from sugarbeet with normal and male sterile cytoplasms, Mol. Gen. Genet., 183, 82-84.

PRING, D. R. AND LEVINGS, UI, c. S. 1978. Heterogeneity of maize cytoplasmic genomes among male-sterile cytoplasms. Genetics, 89, 121-136.

RICX, C. M. 1963. Barriers to interbreeding in Lycopersicon pertviantm. Evolution, 17, 216-232.

RickardS, G. K. 1983, Orientation behavior of chromosome multiples of interchange (reciprocal translocation) hetero- zygotes. Ann, Rev. Genet., 17, 443-498.

SHORE, J. S. AND BARRETT, S. C. H. 1985. Morphological differentiation and crossability among populations of the Turnera ulmifolia L. complex (Turneraceae). Syst. Bot, 10, 308-321.

STEBbinS, G. L. 1958. The inviability, weakness, and sterility of interspecific hybrids. Adv. Gen., 9, 147-215.

STRID, A. 1970. Studies in the Aegean flora. XVI. Biosystematics of the Nigella arvensis complex. Opera Botanica, 28, 1-169.

VAN DAMME, J. M. M. 1983. Gynodioecy in Plantago lanceolata L. II. Inheritance of three male sterility types. Heredity, $\mathbf{5 0}$, 253-273.

VICKERY, R. K. JR., 1959. Barriers to gene exchange within Mimulus guttatus (Scrophulariaceae). Evolution, 13, $300-310$.

VGGEAULT, G. AND zouros, E. 1986. The genetics of asymmetrical male sterility in Drosophila mojavensis and Drosophila arizonensis hybrids: Interactions between the Y-chromosome and autosomes. Evolution, 40, 11601170 .

WARMKE, H. E. AND LEe, S. L. 3. 1977. Mitochondrial degeneration in $\mathrm{T}$ cytoplasmic male-sterile corn anthers. J. Hered, 68, 213-222.

WHITE, м. J. D. 1978. Modes of Speciation. Freeman, San Francisco. 